\title{
Study of Effect of Solution Treatment on Grain Growth Rule of Hastelloy G3 Nickel-Based Alloy Hot Extruded Tube
}

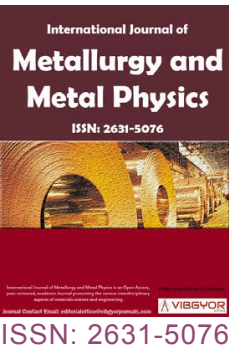

\section{Zhenduo Zhao ${ }^{* *}$, Sha $L i^{1}$, Guangwei Fan ${ }^{1}$ and Jianchun $L i^{2}$}

${ }^{1}$ State Key Laboratory of Advanced Stainless Steel Materials, Taiyuan Iron and Steel (Group) Co., LTD, China

${ }^{2}$ Technology Center, Shanxi Taigang Stainless Steel Co., LTD, China

\begin{abstract}
The Hastelloy G3 nickel-based alloy hot extruded tube was studied in this paper. The effects of solution temperature and holding time on the grain size of the alloy were studied. The results show that when the holding time is constant, the austenite grain size increases with the heat treatment temperature increasing, and the austenite grain coarsening temperature is $1120^{\circ} \mathrm{C}$; when the heat treatment temperature is constant, the austenite grain size of G3 nickel-based alloy grows approximately and parabolically with the holding time increasing. In order to obtain uniform austenite grains, the suitable solid solution system for $\mathrm{G} 3$ alloy hot extruded tube is $1100{ }^{\circ} \mathrm{C}$ and $40 \mathrm{~min}$. Considering the effects of solution temperature, holding time and initial austenite grain size, the austenite grain growth model of G3 nickel-based alloy was deduced. The grain size calculated by this model agrees well with the experimental results.
\end{abstract}

\section{Keywords}

Hastelloy G3, Nickel-based alloy, Solution treatment, Grain growth

\section{Introduction}

With the rapid development of petroleum and natural gas industry and the decreasing exploitation of oil and gas resources, the exploitation of oil and gas resources has to turn to deep wells and ultra-deep wells in complex areas and deep high acid corrosion environments. These acid oil and gas wells have large depth, high pressure and temperature in the well, containing of $\mathrm{CO}_{2}, \mathrm{H}_{2} \mathrm{~S}$ and chloride ion salt with high concentration, which makes the service conditions of the oil casing and harsh. Metal components working in this high corrosive medium environment are very prone to corrosion and frac- ture, and there is a great safety hazard [1-10]. The use of excellent nickel-based alloy materials is an effective way to solve this problem [11-15]. G3 alloy is a representative one of Hastelloy $\mathrm{G}$ series alloys, which is a typical nickel-based corrosion resistant alloy with ultra-low carbon, high $\mathrm{Ni}, \mathrm{Cr}$ and $\mathrm{Mo}$, containing a certain amount of alloying elements such as $\mathrm{Cu}, \mathrm{Co}$ and $\mathrm{W}$, it exhibits a superior corrosion resistance in the strong oxidizing or mixed acid. It is widely used in flue gas desulfurization systems, phosphoric acid production steam generators and heat exchanger. In addition, it is one of the main materials for oil well tubes in high tem-

\footnotetext{
*Corresponding author: Zhenduo Zhao, State Key Laboratory of Advanced Stainless Steel Materials, Taiyuan Iron and Steel (Group) Co., LTD, Taiyuan, 030003, China

Accepted: August 13, 2019; Published: August 15, 2019

Copyright: (C) 2019 Zhao Z, et al. This is an open-access article distributed under the terms of the Creative Commons Attribution License, which permits unrestricted use, distribution, and reproduction in any medium, provided the original author and source are credited.

Zhao et al. Int J Metall Met Phys 2019, 4:037
}

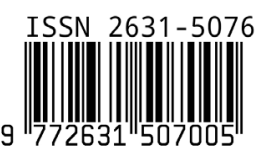


perature, high $\mathrm{H}_{2} \mathrm{~S}, \mathrm{CO}_{2}$ and $\mathrm{Cl}^{-}$riching with acid oil and gas production [16-20]. During the hot working and heat treatment of G3 alloy, the grain growth and precipitation phase often occur, which affects the processing and service performance of the alloy. The researcher's results show that $\mathrm{Cl}^{-}$is harm for the passive film of $\mathrm{G} 3$ and accelerates the corrosion, adding $\mathrm{CO}_{2}$ to the corrosion environment with $\mathrm{H}_{2} \mathrm{~S}$ accelerates the corrosion, the corrosion potential decreases and the stability of the corrosion scale reduces with the increase of $\mathrm{pH}$. The effect of element $\mathrm{S}$ on the corrosion behavior of nickel-base alloy G3 was analyzed and discussed. The results show that the average corrosion rate of nickel-base G3 changes lightly and the thickness of passive film with bipolar structure is about $11 \mathrm{~nm}$ under the element $S$ contents of 0,1 and $10 \mathrm{~g} / \mathrm{L}$. The out layer of passive film is mainly composed of oxides and hydroxides and the inner layer is mainly oxides. However, when the content of element $S$ reaches $100 \mathrm{~g} / \mathrm{L}$, the average corrosion rate of nickel-base G3 increases rapidly, and the thickness of passive film also increases to about $90 \mathrm{~nm}$. The out layer changes greatly and is mainly composed of $\mathrm{Cr}$ and $\mathrm{Ni}$ sulfide, the inner layer is still mainly $\mathrm{Cr}$ and $\mathrm{Ni}$ oxides. The transformation of passive film structure maybe is the main reason that results in the lower corrosion resistance of nickel-base G3. The effect of the solution and aging treatment on the microstructure and precipitated phase of the G3 steel was investigated, the effect of the microstructure change and precipitated phase on the corrosion resistance of G3 steel was analyzed by the corrosion test in high temperature and high pressure environment containing $\mathrm{H}_{2} \mathrm{~S} / \mathrm{CO}_{2}$. The results indicate that the solution treatment temperature should not exceed $1150^{\circ} \mathrm{C}$ in order to avoid the much bigger grains. The carbide $\mathrm{M}_{23} \mathrm{C}_{6}$ precipitated in grain boundaries is increased, and the plate-like carbide $M_{6} C$ is formed inside grains with the aging temperature increasing. The formation of precipitated phase of chrome carbide leads to the severe pitting corrosion of the Ni-based alloy because a poor chromium area has been formed in intergranular sites so that the corrosion resistance of G3 alloys is reduced. The researcher studied the hot deforma- tion behavior and the subsequent microstructure characteristics of Hastelloy G3 alloy by isothermal compression tests at the strain rates of 0.1-10 s-1 and the temperatures of $1050-1200{ }^{\circ} \mathrm{C}$. The results showed that the built material model has good fitting accuracy to satisfy the engineering need. The softening mechanism of G3 alloy is dynamic recrystallization during hot working process. According to the microstructures after deformation, for $\mathrm{G} 3$ alloy the proper deformation temperature is 1180 $1200{ }^{\circ} \mathrm{C}$ and the proper strain rate is $5-10 \mathrm{~s}^{-1}$. The stress-strain curves of corrosion resistant alloys $\mathrm{G} 3$ and the effect of temperature on max stress and reduction of area of alloys have been studied by using Thermomacmaster- $Z$ hot simulator, TEM and SEM, and the effect factors on dynamic recrystallization of alloys were analyzed. Results showed that with increasing temperature compensating factor $Z$, the grain size of dynamic-crystallizing of alloy $\mathrm{G} 3$ decreased. Based on the existing research results of the alloy, it can be found that the main focus is on the corrosion resistance, high-temperature processing characteristics and thermal deformation behavior [21-30]. However, there are few reports on systematic analysis of recrystallization and grain growth behavior of the alloy during the solution treatment. Therefore, studying the grain growth behavior of G3 nickel-based alloy is of great significance for the correct design of the solid solution-strengthened nickel-base alloy heat treatment process and the precise control of the nickel-base alloy tube with an excellent performance. In this paper, the G3 alloy hot extruded tube was taken as the research object, and the grain growth behavior of the alloy in the solution treatment process was studied with different solid solution systems. The kinetic equation of grain growth of the alloy was established, which has an important guiding significance for the formulation of solid solution heat treatment system of G3 alloy.

\section{Experimental}

The Experimental material is $\mathrm{G} 3$ nickel-base alloy hot extruded tube with a size of $\phi 108 \times 15 \mathrm{~mm}$, and its main chemical composition (wt.\%) is shown in Table 1. The solution treatment experiment was carried out in a small box type resistance fur-

Table 1: Chemical composition of the experimental materials (wt.\%).

\begin{tabular}{|l|l|l|l|l|l|l|l|l|l|}
\hline C & $\mathrm{Cr}$ & $\mathrm{Cu}$ & $\mathrm{Mo}$ & $\mathrm{Fe}$ & $\mathrm{Si}$ & $\mathrm{Mn}$ & $\mathrm{Co}$ & $\mathrm{W}$ & $\mathrm{Ni}$ \\
\hline 0.011 & 22.97 & 1.94 & 7.06 & 20.05 & 0.33 & 0.52 & 2.32 & 0.85 & Bal \\
\hline
\end{tabular}




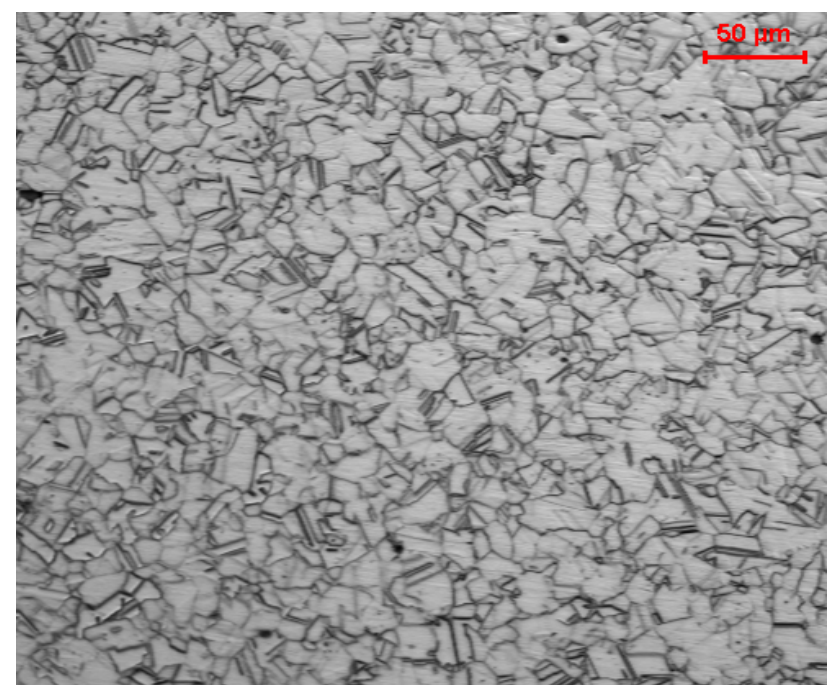

Figure 1: Microstructures of G3 alloy hot extruded seamless tube. nace. The solution temperature was $1050{ }^{\circ} \mathrm{C}, 1080$ ${ }^{\circ} \mathrm{C}, 1100{ }^{\circ} \mathrm{C}, 1120^{\circ} \mathrm{C}$, and the holding time was 20 min, $40 \mathrm{~min}, 60 \mathrm{~min}$. The solution treatment was completed and the water was cooled. The metallographic specimens were cut off from the solution treatment samples, and then roughly ground, finely polished, and etched by etched by a solution of 1.5 $\mathrm{g} \mathrm{CuSO}_{4}$ and $40 \mathrm{ml} \mathrm{HCl}$ and $20 \mathrm{ml}$ alcohol. The specimens etched were cleaned with an alcohol solution and dried. The austenite grain morphology was observed and analyzed with an optical microscope of the Neuphoto 21 type. The average austenite grain size of the samples was measured and analyzed by Image-Pro Plus image analysis software according to GB/T 6394-2002 (a chinese stand named method for measuring the average grain size of metals).
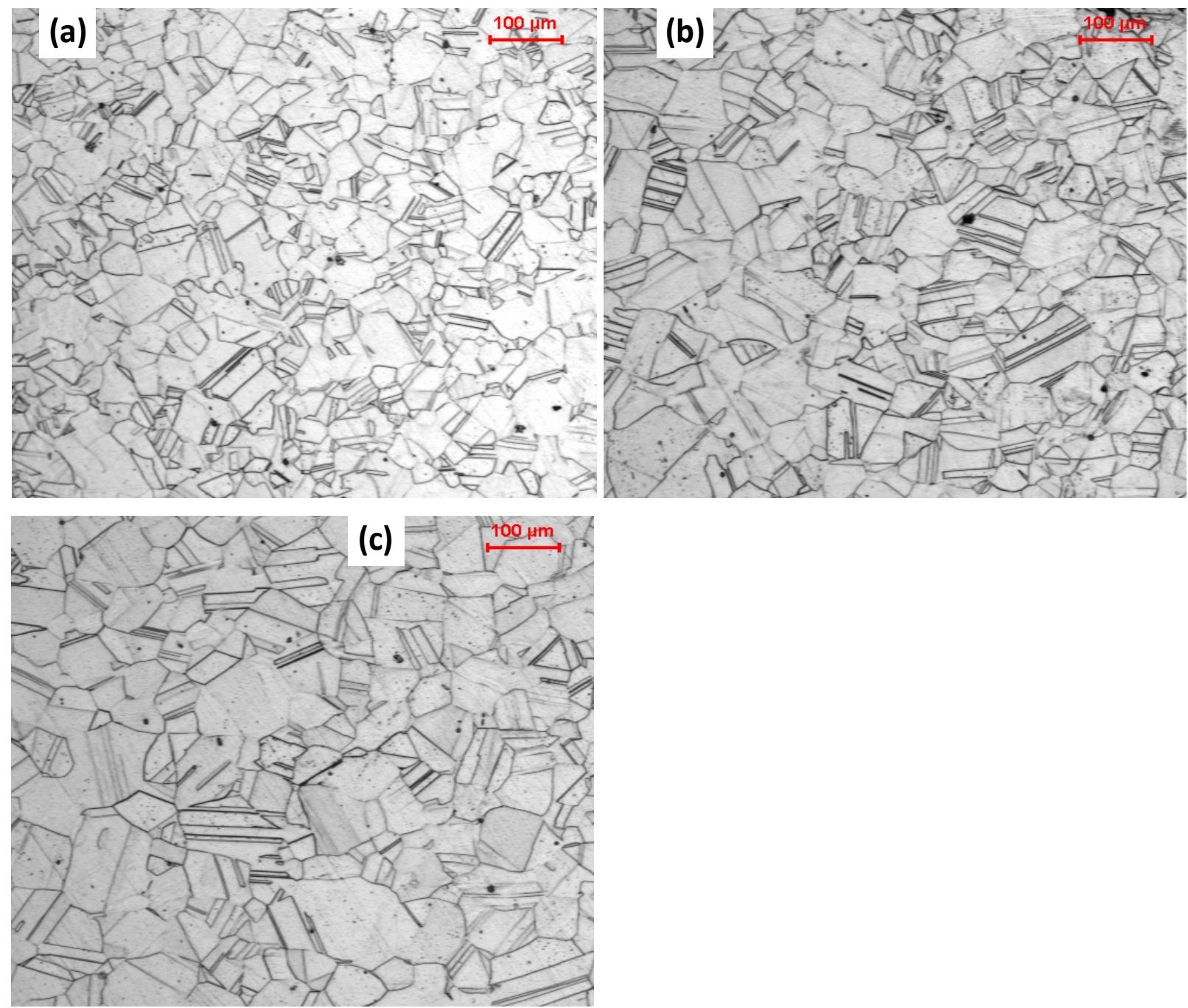

Figure 2: Austenite grain morphology of $\mathrm{G} 3$ alloy holding for 20 minutes at different temperatures: a) $1050{ }^{\circ} \mathrm{C}$; b) $1080^{\circ} \mathrm{C}$; c) $1120^{\circ} \mathrm{C}$. 


\section{Results and Discussion}

\section{The original microstructure of the G3 alloy tube}

Figure 1 shows the metallographic microstructure of the $\mathrm{G} 3$ alloy tube after hot extrusion. It can be seen that the alloy matrix is a typical austenite microstructure with uniform equiaxed grains, the grains are fine and uniformly distributed. The grain degree is level 8.0 and the grain size is about 20.5 $\mu \mathrm{m}$.

\section{Grain growth behavior in solid solution process}

Effect of heat treatment temperature on grain growth: Figure 2 shows the austenite grain morphology after holding for 20 minutes at different temperatures. Figure 3 shows the austenite grain size after holding for 20-60 minutes at different temperatures. It can be seen that when the temperature is $1050-1080{ }^{\circ} \mathrm{C}$, the austenite grain growth rate is lower and the grain size is more uniform, the grain size is in the range of 56.5-71.6

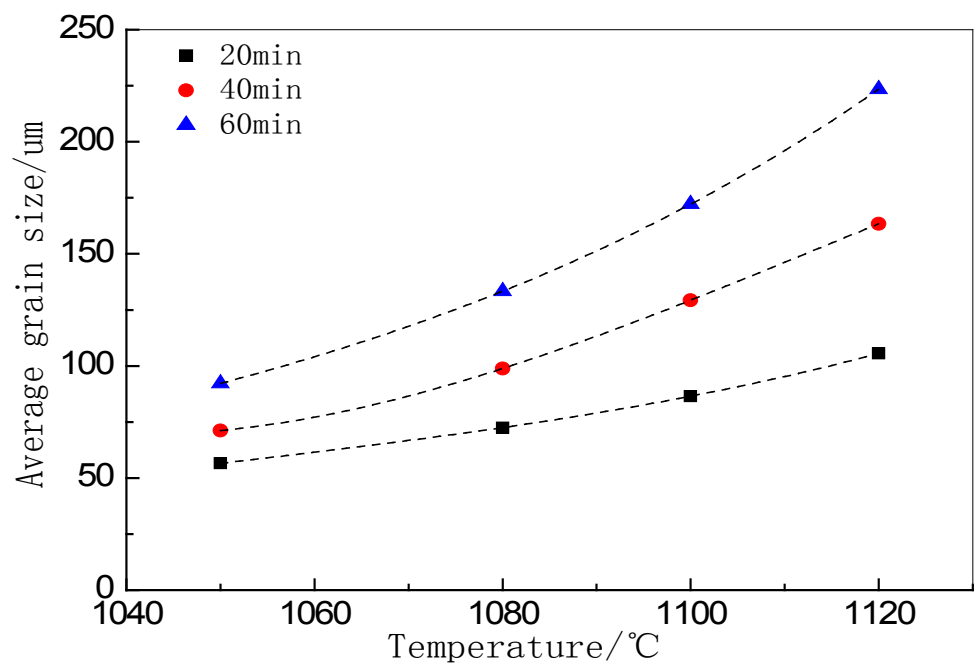

Figure 3: Variation of austenite grain size with temperature holding for 20-60 min.
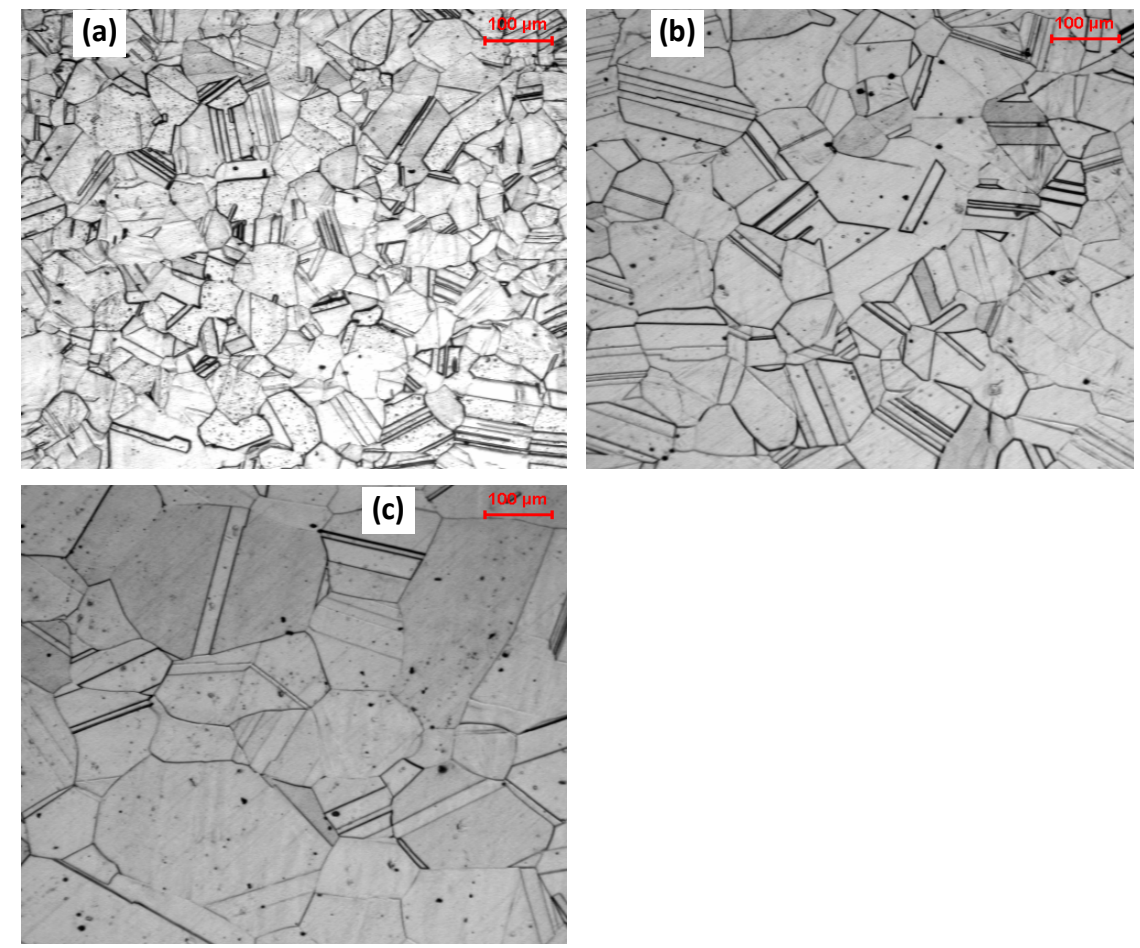

Figure 4: Austenite grain structures of $\mathrm{G} 3$ alloy heated at $1100{ }^{\circ} \mathrm{C}$ with different holding time: a) $20 \mathrm{~min}$; b) 40 $\min$; c) $60 \mathrm{~min}$. 
$\mu \mathrm{m}$; when the temperature is $1120^{\circ} \mathrm{C}$, the austenite grain growth rate is obviously accelerated and the mixed crystal structures appear. The austenite grain growth process is a thermal activation process, and the increase of temperature will promote the grain growth. In addition, the complete dissolution temperature of the precipitates $\mathrm{M}_{23} \mathrm{C}_{6}$ with high $\mathrm{Cr}$ and $\mathrm{Mo}, \mathrm{M}_{6} \mathrm{C}$ and other carbides in the $\mathrm{G} 3$ alloy are about $1060^{\circ} \mathrm{C}$. With the increase of temperature, these second phases gradually dissolve, and the resistance to grain boundary migration decreases, which will also accelerate austenite grain growth. Figure 4 shows the austenite grain morphology of the alloy after holding at $1100{ }^{\circ} \mathrm{C}$ for different times, the grain size grows obviously with the increasing of the holding time.

The effect of temperature on grain growth is mainly the influence of the atomic migration and diffusion process at the grain boundary of the alloy. When the holding time is given, the Arrhenius relationship [31,32] can be used to describe the grain growth process:

$$
M=M_{0} \exp (-Q / R T)
$$

In the formula, $\mathrm{M}$ is the migration rate of grain boundaries, which determined the growth rate and growth process of new phases, its unit is $m / s ; M_{0}$ is the material-related constant; $Q$ is the apparent activation energy of grain boundary migration, its unit is $\mathrm{J} / \mathrm{mol}$; $\mathrm{R}$ is a gas constant, which is $8.31 \mathrm{~J} /$ ( $\mathrm{mol} \mathrm{K}) ; \mathrm{T}$ is thermodynamic temperature, its unit is $\mathrm{K}$. it can be seen from Figure 3 that the average grain size of austenite grows exponentially with the increase of temperature, which well reflects the exponential growth rate of austenite grain in Arrhenius relationship with the increase of temperature.

Effect of holding time on grain growth: Figure 5 shows the austenite grain morphology of the alloy after holding at $1120^{\circ} \mathrm{C}$ for different times. Figure 6 shows the effect of different holding times on austenite grain growth at different temperatures. It can be seen that in the temperature range of 1050 ${ }^{\circ} \mathrm{C} 1080{ }^{\circ} \mathrm{C}$, the austenite grain size grows slowly with the increase of the holding time from 20.5 $\mu \mathrm{m}$ to $92.2 \mu \mathrm{m}$ and $133.3 \mu \mathrm{m}$, respectively, and the grain degree increases from level 8.0 to level 4.0 and level 3.0, respectively. When the temperature is $1120^{\circ} \mathrm{C}$ and the holding time is $20 \mathrm{~min}$, the grains grow slowly and exhibit some characteristics of mixed grains structure. The growth rate increases obviously when the holding time is more than $20 \mathrm{~min}$. With the increasing of the holding time, the grain size grows obviously, the degree of mixed
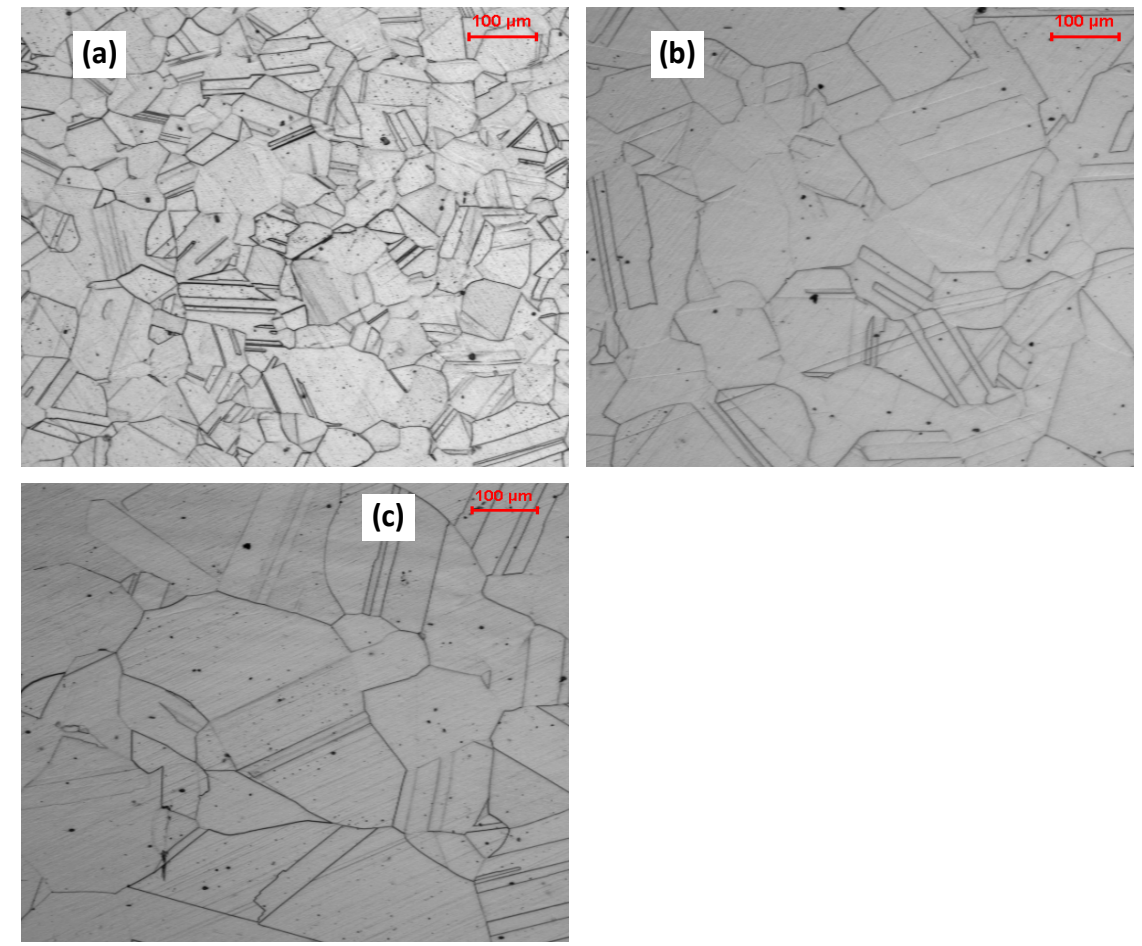

Figure 5: Austenite grain morphology heated at $1120{ }^{\circ} \mathrm{C}$ for different holding times: a) 20 min; b) 40 min; c) 60 $\min$. 


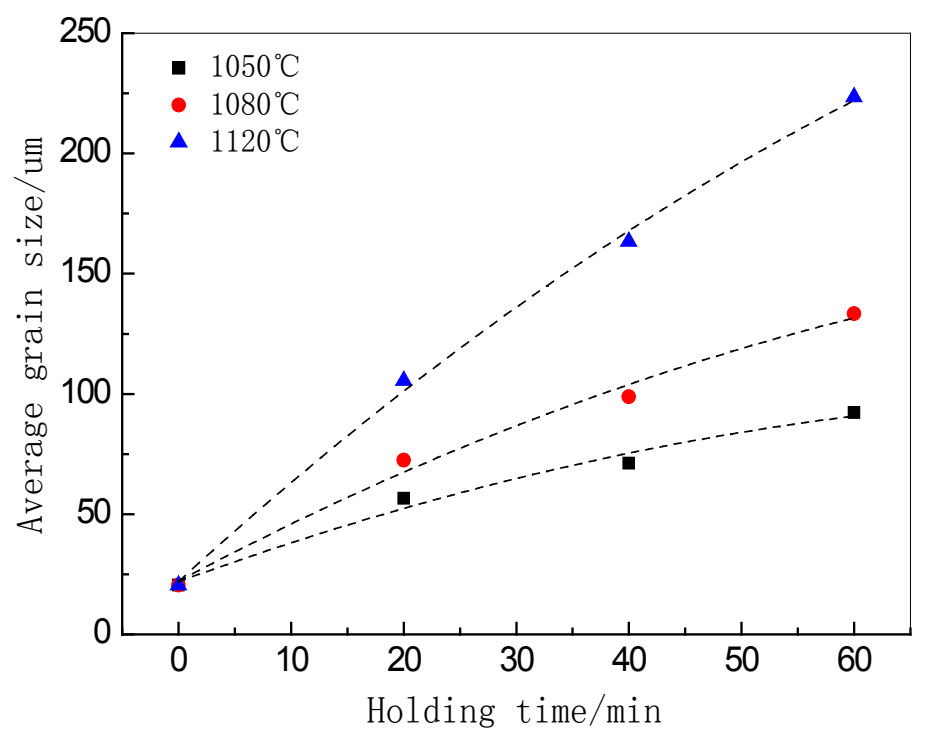

Figure 6: Relationship between average grain size and holding time of G3 alloy at different temperatures.

grains decreases. The microstructure is relatively uniform, the grain size increases from $20.5 \mu \mathrm{m}$ to $223.5 \mu \mathrm{m}$, and the grain size grade grows from Level 8.0 to Level 1-2. This is due to the high energy of some grain boundaries when the holding time is 20 minutes for a short time. In order to maintain the system equilibrium, the grain boundary interface can spontaneously decrease, and some austenite grains grow rapidly. With the holding time extended to 40-60 $\mathrm{min}$, the austenite grain size gradually becomes uniform, the grain boundary becomes more and more straight, the driving energy of grain growth decreases, and the grain growth rate slows down.

When the austenite grains grow normally under the isothermal conditions, the variation curve of the average austenite grain size with holding time is approximately parabola, which can be described by Beck equation [33]:

$$
D=K t^{\mathrm{n}}
$$

In the formula, $D$ is the average grain size at a certain holding time, its unit is $\mu \mathrm{m} ; \mathrm{K}$ and $\mathrm{n}$ are constants related to the material and temperature; $t$ is the holding time, its unit is $s$. it can be seen from Figure 6 that the average grain size of austenite approximates a parabolic trend with the prolongation of holding time, which better reflects the Beck relationship. The results show that in order to obtain austenite with an uniform grain size and homogeneous microstructure, the solution temperature should be controlled at $1100{ }^{\circ} \mathrm{C}$ and the holding time should be controlled at $40 \mathrm{~min}$.

\section{Grain growth model}

During the solution treatment, the heating temperature, holding time and the size of the initial austenite grains have an important effect on the austenite grain size. The austenite grain size of the original alloy tube is $20.5 \mu \mathrm{m}$. Therefore, the grain growth process during the solid solution should consider the effect of the original austenite grain size. Under isothermal conditions, the relationship between average grain size and time of austenite can be predicted by the model $[34,35]$ proposed by C.M. Sellars and E. Anelli. See formula (3), it is suitable for the prediction of grain growth structure without grain boundary precipitates.

$$
D^{\mathrm{n}}=D_{0}^{\mathrm{n}}+A t^{\mathrm{m}} \exp \left(-\frac{\mathrm{Q}}{\mathrm{RT}}\right)
$$

In the formula, $D$ is the average grain size under a certain holding time, its unit is $\mu \mathrm{m} ; D_{0}$ is the initial austenite grain size, its unit is $\mu \mathrm{m}$; $t$ is the holding time, its unit is s; $T$ is the heating temperature, its unit is k; $Q$ is the activation energy of grain growth, its unit is $\mathrm{J} / \mathrm{mol} ; \mathrm{R}$ is a gas constant, it is $8.31 \mathrm{~J} /(\mathrm{mol}$ - $\mathrm{K}) ; \mathrm{A}, \mathrm{n}$ and $\mathrm{m}$ are constants.

By taking logarithms on both sides of formula (3), we can get

$$
\ln \left(D^{\mathrm{n}}-D_{0}^{\mathrm{n}}\right)=\ln A+\operatorname{mlnt}-\frac{Q}{R T}
$$

For formula (4), the test data are determined by linear regression with given $\mathrm{n}$ values $(0.5,1.0$, 1.5, 2.0, 2.5, 3.0, 3.5). The specific determination 


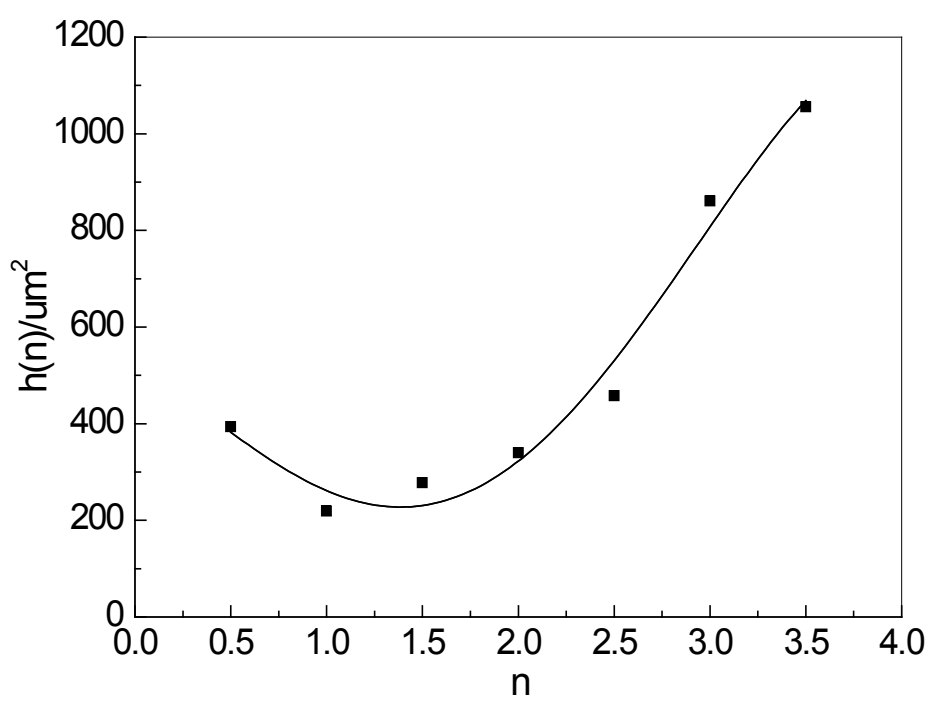

Figure 7: Error function polynomial fitting.

methods are as follows:

$m$ value determination method:

Under certain conditions of heating temperature, the formula (4) is biased:

$$
\mathrm{m}=\partial\left[\ln \left(D^{n}-D_{0}^{n}\right)\right] / \partial(\ln t)
$$

Formula (5) shows that the relationship curve between the two is obtained by drawing pairs and linear regression is carried out. The average slope is $\mathrm{m}$.

$Q$ value determination method:

Under certain conditions of holding time, the formula (5) is biased:

$$
Q=-R \partial\left[\ln \left(D^{n}-D_{0}^{n}\right)\right] / \partial(1 / T)=-R \mathrm{k}
$$

Formula (5) shows that the relationship curve between the two can be obtained by plotting and linear regression. The average slope $k$ is calculated, and the activation energy of grain growth $Q$ can be calculated by $\mathrm{k}=-Q / \mathrm{R}$.

\section{A value determination method:}

At a given temperature and holding time, the values of $Q, \mathrm{~m}, \mathrm{t}, T, D$ and $D_{0}$ are substituted into formula (4) to calculate the A value.

The calculation method of the appropriate value is as follows: the error function is introduced, and the theoretical grain size $D$ is calculated by the grain growth equation obtained by the above-mentioned different $n$ values, and the sum of the squares of the measured grain size values is subtracted from all calculated values, namely:

$$
h(n)=\sum_{\mathrm{i}}\left(D_{i}^{\prime}-D\right)^{2}
$$

The scatter plot is shown in Figure 7. It can be seen from Figure 7 that there is a minimum value of the error function, and the corresponding $n$ value is a better grain growth index, and that fitting Figure 6 with four polynomials is used to obtain the function (8):

$\mathrm{h}(n)=521.20-228.02 n-180.45 n^{2}+175.01 n^{3}-26.31 n^{4}$

The polynomial fitting curve in Figure 7 is differentiated and the $\mathrm{n}$ value is 1.20 when the derivative is equal to 0 . This value is the grain growth index of G3 alloy in the process of solid solution.

When the $\mathrm{n}$ value is 1.20 , the relationship curve between $\ln D-\operatorname{lnt}$ and $\ln \left(D-D_{0}\right)-1 / T$ was plotted, which is seen from Figure 8 , the $m$ value is 0.78 and the $Q$ value is $2.41 \times 10^{5} \mathrm{~J} / \mathrm{mol}$ can be obtained by linear fitting and the value $A$ which is $1.05 \times 10^{9}$ can be determined by substituting formula (4) by the value of $m$ and $Q$. Therefore, the equation for solid solution treatment of grain growth of G3 alloy is:

$$
D^{1.20}=D_{0}^{1.20}+1.05 \times 10^{9} t^{0.78} \exp \left(-\frac{2.41 \times 10^{5}}{R T}\right)
$$

In order to verify the accuracy and validity of the grain growth model of G3 alloy, the grain size of G3 alloy under the different heat treatment temperatures and holding times was calculated according to formula (9), and compared with the measured value, as shown in Figure 9. By comparison, the 

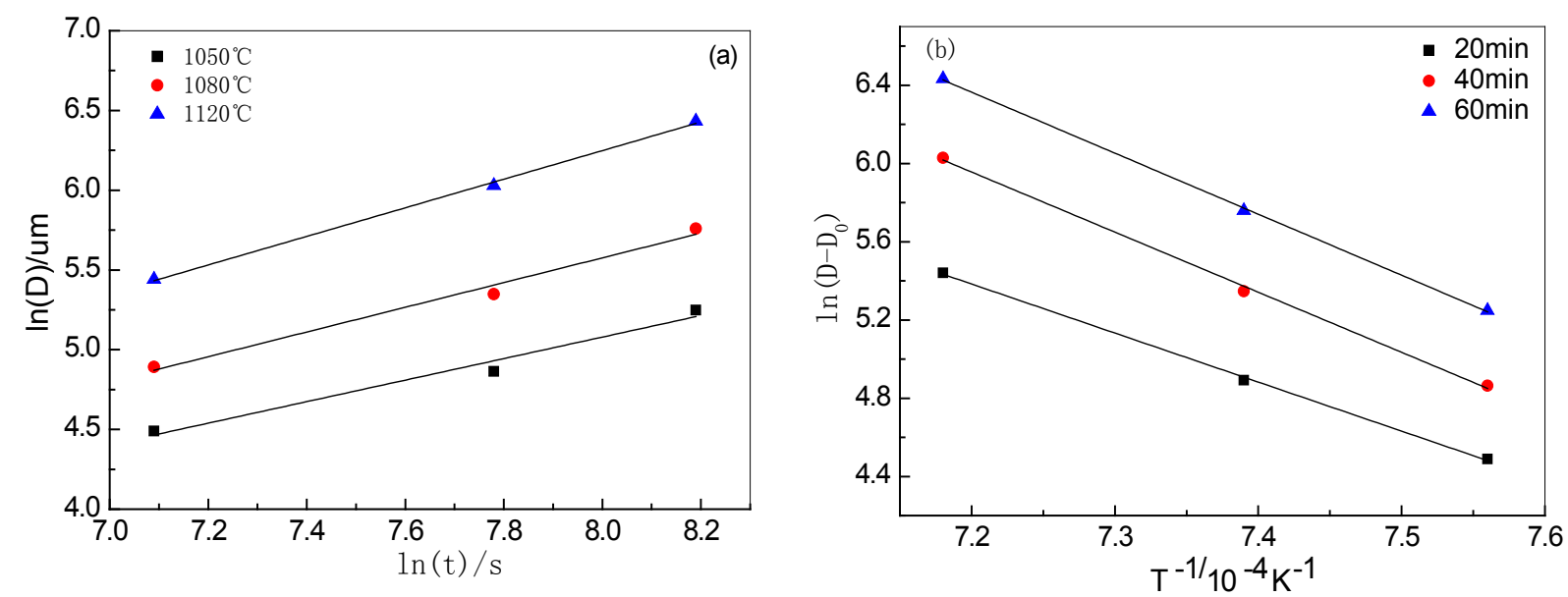

Figure 8: Relationship curves of $\ln D-\ln$ and $\ln \left(D-D_{0}\right)-1 / T$.

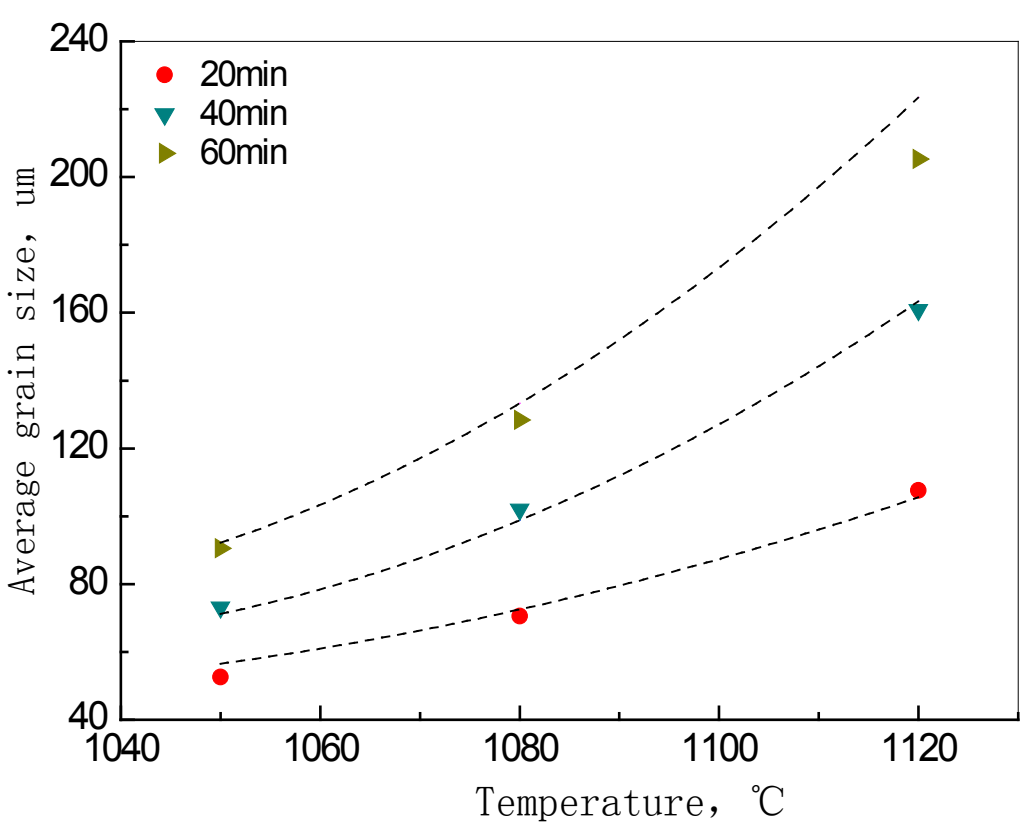

Figure 9: Comparison between the grain size of the calculation results and the experimental results. (Curve represents the experimental value, the point indicates the predicted value).

grain size prediction results predicted by the model agree well with the actual situation, and the error between the calculated value and the measured value is not more than $8 \%$.

\section{Conclusions}

The study on the grain growth rule of G3 alloy hot extruded tube during solid solution treatment shows that:

(1) When the holding time is constant, the austenite grain size of $\mathrm{G} 3$ alloy grows exponentially with the increase of the heat treatment temperature. When the temperature is $1120^{\circ} \mathrm{C}$, the grain begins coarsening.
(2) When the heat treatment temperature is constant, the austenite grain size grows parabolically with the increase of the holding time. In order to obtain uniform austenite grains, the suitable solid solution system for $\mathrm{G} 3$ alloy hot extruded tube is $1100{ }^{\circ} \mathrm{C}$ and $40 \mathrm{~min}$.

(3) In the process of solid solution treatment of G3 alloy, considering the effects of heat treatment temperature, holding time and initial austenite grain size, the austenite grain growth model under isothermal conditions for G3 alloy is derived:

$$
D^{1.20}=D_{0}^{1.20}+1.05 \times 10^{9} t^{0.78} \exp \left(-\frac{2.41 \times 10^{5}}{R T}\right) . \quad \text { The }
$$


calculated results of the model agree well with the experimental data.

\section{Acknowledgments}

This work was financially supported by the Youth Top Talents Support Project of Shanxi Province (201606) and the Natural Science Foundation of Shanxi Province (No. 201801D121081).

\section{References}

1. Mudali U, Shankar P, Ningshen S, Dayal R, Khatak $H$ (2002) On the pitting corrosion resistance of nitrogen alloyed cold worked austenitic stainless steels. Corrosion Science 44: 2183-2198.

2. Gu CY, Di QF, Wang ZH (2006) Stress corrosion performance of N80 steel in formation water. Acta Petrolei Sinica 27: 141-144.

3. Zhao XW, Luo JH, Zheng MS, Li HL, Zhang H (2006) Method for predicting remaining life of pipeline with dispersion-type corrosion damage. Acta Petrolei Sinica 27: 119-123.

4. Shaikh H, Anita T, Poonguzhali A, Amirthalingam R, Khatak $H$ (2006) Effect of high temperature aging on the corrosion behavior of nitrogen-added AISI type 316L stainless steel. Trans Ind Inst Met 59: 271-282.

5. Bana'SJ, Borkowska UL, Mazurkiewicz B, Solarski W (2007) Effect of $\mathrm{CO} 2$ on $\mathrm{H} 2 \mathrm{~S}$ the composition and stability of passive film on iron alloys in geothermal water. Electrochimica Acta 52: 5704-5714.

6. Chen CF, Fan CW, Zheng SQ, Zhang GA, Ge L, et al. (2008) XPS analysis of surface of G3 nickel base alloy under high $\mathrm{H} 2 \mathrm{~S}$ and $\mathrm{CO} 2$ partial pressure. The Chinese Journal of Nonferrous Metals 18: 2050-2055.

7. Lamic AF, Daudin A, Brunet $S$, Legens $C$, Bouchy $C$, et al. (2008) Effect of H2S partial pressure on the transformation of a model FCC gasoline olefin over unsupported molybdenum sulfide-based catalysts. Applied Catalysis A: General 344: 198-204.

8. Tong $\mathrm{M}$, Bao $\mathrm{YZ}$, Dong $\mathrm{H}$, Su J, Wang $\mathrm{LH}$, et al. (2009) High temperature deformation characteristics of G3 and 825 alloy used in oil pipes of high-sour gas fields. Materials For Mechanical Engineering 33: 56-58.

9. Yin ZF, Zhao WZ, Bai ZQ, Feng YR, Zhou WJ (2008) Corrosion behavior of SM 80SS tube steel in stimulant solution containing HS partial pressure on the transformation of a model FCC gasoline olefin over unsupported molybdenum sulfide-based catalysts. Applied Catalysis A: General 344: 198-204.

10.Chen CF, Jiang RJ, Zhang GA, Zheng SQ, Ge L (2010)
Study on local corrosion of nickel-base alloy tube in the environment of high temperature and high pressureH2S/CO2. Rare Metal Materials and Engineering 39: 427-432.

11.Takeuchi M, Nakajima $Y$, Hoshino K, Kawamura F (2010) Controls of chromium and third element contents in nickel-base alloys for corrosion resistant alloys in hot HNO3-HF mixtures, J Alloy Compd 506: 194-200.

12.Roy AK, Venkatesh A (2010) Evaluation of yield strength anomaly of alloy 718 at $700-800^{\circ} \mathrm{C}$. J Alloy Compd 496: 393-398.

13.Zhen Li, Han J, Lu J, Chen J (2015) Cavitation erosion behavior of hastelloy C-276 nickel-based alloy. J Alloy Compd 619: 754-759.

14.Wang L, Liu F, Cheng JJ, Zuo Q, Chen CF (2015) Hot deformation characteristics and processing map analysis for nickel-based corrosion resistant alloy. J Alloy Compd 623: 69-78.

15.Jothi S, Merzlikin SV, Croft TN, Andersson J, Brown SGR (2016) An investigation of micro-mechanisms in hydrogen induced cracking in nickel-based superalloy 718. J Alloy Compd 664: 664-681.

16.Kopliku A, Scoppio L (2003) Selecting materials for an offshore development characterized by sour and high salinity environment. Corrosion, Houston: NACE, USA, 03128.

17.Wang C, Ju SH, Yan SL (2009) Research progress of nickel-based corrosion resistant alloys. Materials Review 23: 71-76.

18. Masayuki S, Yohei O, Hisashi A, Shigemitsu K, Masaaki I, et al. (2011) Development of high-strength $\mathrm{Ni}$ alloy OCTG material for source environment. NACE Corrosion 2011 Conference \& Expo, Houston: NACE, 11109.

19. Hibner EL, Puckett BC, Patchell JK (2004) Comparison of corrosion resistance of nickel-base alloys for OCTG'S and mechanical tubing in severe sour service conditions. Corrosion, Houston: NACE, 04110.

20.Tabinor M, Bailey B, Cheldi T, Nice PI, Torella R, et al. (2006) Corrosion and environmental cracking behavior of three corrosion resistant alloys at various expansion ratios. Corrosion, Houston: NACE, 06152.

21.Bao YZ, Dong H, Su J, Yong QL, Wang LH, et al. (2009) Study on hot workability of corrosion resistant alloys G3, G3-Z and 825. Special Steel 30: 1-3.

22.Cui SH, Li CF, Rong JF, Ren Q (2009) Study on the factors affecting corrosion of nickel-based alloy G3 in high $\mathrm{H} 2 \mathrm{~S} / \mathrm{CO} 2$ environment. Journal of Materials Science and Engineering 38: 29-34. 
23.Qian JS, Chen CF, Li SY, Zheng SQ, Weng YJ (2012) Effect of element $S$ on corrosion behavior of nickelbased alloy $\mathrm{G} 3$ in high temperature and high pressure $\mathrm{H} 2 \mathrm{~S} / \mathrm{CO} 2$ atmosphere. Chinese Journal of Nonferrous Metals 22: 2214-2222.

24.Li DP, Lu MX, Zhang L, Chen LJ (2012) Effect of heat treatment temperature on intergranular corrosion behavior of G3 alloy. Journal of Materials Heat Treatment 33: 22-26.

25.Zhang X, Li HW, Zhan M (2018) Mechanism for the macro and micro behaviors of the $\mathrm{Ni}$-based superalloy during electrically-assisted tension: Local joule heating effect. J Alloy Compd 742: 480-489.

26. Wang H, Fang DM, Chuang KT (2008) A sulfur removal and disposal process through $\mathrm{H} 2 \mathrm{~S}$ adsorption and regeneration: Ammonia leaching regeneration. Process Safety and Environment Protection 86: 296-302.

27.Azevedo CRF (2007) Failure analysis of a crude oil pipeline. Engineering Failure Analysis 14: 978-994.

28.Stefanov P, Stoychev D, Stoycheva M, Marinova T (2006) XPS and SEM studies of chromium oxide films chemically formed on stainless steel 316L. Materials Chemistry and Physics 65: 212-215.

29. Kamachi-Mudali U, Reynders B, Stratmann M (1999)
Localized corrosion behavior of Fe-N model alloys. Corros Sci 41: 179-189.

30.Tang JQ, Gong JM, Zhang XC, Tu ST (2006) Comparison on the cracking susceptibility of different low alloy steel weldments exposed to the environment containing wet H2S. Engineering Failure Analysis 13: 1057-1064.

31.Liu JT, Zhang YF, Tao Y, Liu GQ, Hu BF (2006) Grain growth behavior during heat treatment of FGH96 alloy forging disc blank. Metal Heat Treatment 31: 40-44.

32. Chen LQ, Yan FL, Liu XH (2009) Grain growth model of Inconel 718 alloy billet rough rolling heating process. Journal of Metals 45: 1242.

33. Hu LG, Xie XW (2014) Heat treatment of steel. $\left(4^{\text {th }}\right.$ edn), Xi'an: Northwestern Polytechnical University Press, China, 14-37.

34.Devadas C (1991) The thermal and metallurgical state of steel strip during hot rolling: Part3. Microstructural evolution. Metallurgical Transactions A 22: 335-342.

35.Bambach M, Seuren S (2015) On instabilities of force and grain size predictions in the simulation of multi-pass hot rolling processes. Journal of Materials Processing Technology 216: 95-113. 